\title{
Thymidine Kinase 1: A Universal Marker for Cancer
}

\author{
Melissa M. Alegre ${ }^{1}$, Richard A. Robison ${ }^{1} \&$ Kim L. O’Neill ${ }^{1}$ \\ ${ }^{1}$ Department of Microbiology and Molecular Biology, Brigham Young University, Provo, USA \\ Correspondence: Dr. Kim O'Neill, 855 WIDB, Brigham Young University, Provo, UT, 84602, USA. Tel: \\ 1-801-422-2449, Fax: 1-801-422-0519. E-mail: kim_oneill@byu.edu
}

Received: April 3, 2013 Accepted: April 24, 2013 Online Published: May 1, 2013

doi:10.5539/cco.v2n1p159 URL: http://dx.doi.org/10.5539/cco.v2n1p159

\begin{abstract}
Thymidine Kinase 1 (TK1) is traditionally a serum biomarker which is elevated in the early stages of malignancies. TK1 is a DNA repair enzyme which is typically associated with proliferation. In serum, TK1 is elevated in a stage-like manner and increases as the disease advances. As a well-characterized serum biomarker, relatively little work has been done to establish it as a tumor biomarker. However, tumor TK1 reflects many of the same trends that can be seen with serum TK1. Specifically, tumor TK1 is an early event in tumor progression and increases with grade and stage. This study seeks to demonstrate that, similar to serum TK1, tumor TK1 is a valuable indicator of malignancy in the most common types of cancer in men. In this study we used a highly specific monoclonal antibody to TK1 to histologically stain 10 different types of carcinoma tissue and corresponding normal tissue. We found that TK1 is a good marker for malignancy and is significantly overexpressed in cancers compared to normal controls in lung, colon, prostate, esophagus, stomach, liver, and kidney tissues. Slight differences were found in the staining pattern among various types of lung cancer although virtually all types showed significantly higher TK1 staining compared to normal tissue. Additionally, TK1 expression in prostate carcinoma was significantly higher than normal tissue, and correlated with an increase in grade. Overall, it is clear that TK1 is a valuable cancer marker in a wide variety of solid tumors and may be considered a universal cancer marker.
\end{abstract}

Keywords: prostate cancer, lung cancer, TK1, thymidine kinase 1

\section{Introduction}

Cancer is the second leading cause of death in the United States but is the number one cause of death in individuals ages 40 to 79 years (Siegel, Naishadham, \& Jemal, 2013). In men, the two most prevalent cancer sites which contribute to cancer mortality are lung and prostate. Together these account for approximately $38 \%$ of cancer deaths in men (Siegel et al., 2013). Although many biomarkers have been identified in the hopes of reducing cancer mortality rates, few have been successful. However, thymidine kinase 1 (TK1) may have independent potential to reduce cancer mortality rates through early detection.

TK1 is a biomarker which is involved in DNA repair and is upregulated during S phase (He, Skog, \& Tribukait, 1991). It is considered a proliferation marker and is often compared with Ki67 and/or proliferating cell nuclear antigen (PCNA). Several studies have shown that TK1 is more useful as a proliferation marker than either Ki67 or PCNA (Guan et al., 2009; He et al., 2004; Z. H. Huang et al., 2012). TK1 has primarily been studied as a diagnostic and prognostic tool found in the serum of cancer patients. TK1 is elevated in a stage-specific manner in a variety of solid and hematological malignancies (Aufderklamm et al., 2012). For example, TK1 has been established as a serum biomarker in breast cancer, lung cancer, colon cancer, malignant melanoma, gastric cancer, non-Hodgkin's lymphoma, chronic lymphocytic leukemia, acute lymphoblastic leukemia, and acute myeloid leukemia in addition to several other cancer types (Li et al., 2010; Liu et al., 2011; O'Neill, Zhang, Li, Fuja, \& Murray, 2007; Wu et al., 2013; Xu et al., 2009). TK1 is elevated in the very early stages of cancer and has even been found elevated in the precancerous stages (S. Huang et al., 2011). In fact, in a health screen of 35,365 individuals $0.8 \%$ had elevated serum TK1, and $8.8 \%$ of those with elevated TK1 went on to develop new malignancies or had progression of their pre-malignancies (Chen et al., 2011). Recent studies have also found that TK1 shows similar trends in tumors. In breast cancer patients, TK1 was overexpressed in atypical ductal hyperplasia, precancerous lesions, and also in carcinoma tissue (Alegre, Robison, \& O'Neill, 2012; Guan et al., 2009). Although TK1 has been well-characterized as a serum biomarker and similar trends are seen with tumor TK1, this study seeks to compare TK1 expression in a variety of solid tumors. In particular, we compare TK1 
expression within the two most common types of cancer in men: prostate and lung, to possibly establish TK1 as a candidate marker for the major forms of cancer in men.

\section{Methods}

\subsection{Patient Samples}

All the following arrays were analyzed for TK1 expression using a highly-specific anti-TK1 monoclonal antibody (CB001) (O'Neill, Buckwalter, \& Murray, 2001). A multi-organ tissue array containing carcinoma tissue from 9 different organs of 30 individuals and normal controls of 7 different organs from 48 individuals were analyzed for TK1 expression. Carcinoma tissue included liver $(n=6)$, stomach $(n=6)$, esophagus $(n=6)$, kidney $(n=6)$, uterus $(n=5)$, colon $(n=6)$, brain $(n=6)$, muscle $(n=6)$, and lung $(n=6)$. Normal tissue included liver $(\mathrm{n}=6)$, stomach $(\mathrm{n}=6)$, esophagus $(\mathrm{n}=6)$, kidney $(\mathrm{n}=6)$, colon $(\mathrm{n}=6)$, rectum $(\mathrm{n}=6)$, and lung $(\mathrm{n}=6)$. Prostate tissue arrays included tissue from prostate carcinoma $(n=32)$, normal prostate $(n=17)$ and prostate hyperplasia $(n=6)$. True normal tissue arrays included tissue from 100 individuals and 34 organs (Cybrdi Inc, Frederick MD). Lung tissue arrays included lung cancer tissue $(\mathrm{n}=376)$ from 172 individuals and normal lung tissue $(\mathrm{n}=63)$ from 29 individuals (Cybrdi Inc, Frederick MD). Lung cancer tissue included small cell carcinoma $(n=37)$, large cell carcinoma $(n=19)$, adenocarcinoma $(n=26)$, squamous cell carcinoma $(n=36)$, sarcoma $(n=2)$, adenosquamous cell carcinoma $(n=4)$, bronchioloalveolar carcinoma $(n=5)$, mucinous adenocarcinoma $(n=1)$, mesothelioma $(\mathrm{n}=2)$, undifferentiated carcinoma $(\mathrm{n}=4)$, neuroendocrine carcinoma $(\mathrm{n}=3)$, and papillary carcinoma $(\mathrm{n}=1)$.

\subsection{Immunohistochemistry}

Each of the tissue arrays were stained using an anti-TK1 monoclonal antibody (CB001) and an isotype control (mouse IgG, Upstate Company, 12-371). The staining procedure is as previously described (Alegre et al., 2012). Briefly, the tissues were deparafinized and rehydrated. After antigen retrival with $0.01 \mathrm{M}$ Sodium Citrate buffer ( $\mathrm{pH}$ 6.0) and blocking for endogenous peroxidase activity, slides were blocked (10\% normal horse serum) and then incubated for 3 hours with CB001 or isotype control $(0.6 \mathrm{ug} / \mathrm{ml})$. After washing, slides were incubated with biotin-conjugated anti-mouse secondary antibody (Vector Labs Inc.), washed again, and incubated with Streptavidin-Peroxidase (ABC Kit, Vector Labs Inc.). Slides were developed using diaminobenzidine (Vector Labs Inc.) and counterstained with haematoxylin.

\subsection{Statistical Analysis and Scoring}

Each tissue specimen was scored by three independent pathologists and given a consensus score of negative, weak positive, or positive. Additionally, the lung tissue arrays were scored using a fourth category of strong positive. In each case, a positive score was associated with staining in $5-25 \%$ of tumor cells. A weak positive score indicated that although some staining was present, it was insignificant compared to the isotype control. A negative score was associated with no staining. Additionally, a strong positive score for the lung arrays indicated $>25 \%$ of tumor cells showed TK1 expression. Statistical analysis of the tissue specimens included a chi square test of independence and $\mathrm{p}<0.05$ (two-sided) was regarded as statistically significant.

\section{Results}

\subsection{A Universal Cancer Marker: TK1 Expression}

TK1 expression was evaluated using a highly specific monoclonal antibody in histological slides of 9 different carcinoma tissues from 30 individuals including brain, esophagus, stomach, colon, liver, lung, kidney, uterine, and muscle. TK1 expression was also evaluated in 8 different normal tissues from 48 individuals including esophagus, stomach, liver, uterine, colon, rectum, lung, and kidney. Three independent pathologists scored each tissue and TK1 cytoplasmic staining was detected in hepatocellular carcinoma, clear cell carcinoma of kidney, uterus rhabdomyosarcoma, esophageal squamous cell carcinoma, and adenocarcinoma of the uterus, stomach, colon, and lung (Figure 1). On the other hand, weak positive TK1 expression was found in 3 cases of meningioma indicating that although some signal was present, it was insignificant compared to the isotype control. No TK1 staining was detected in normal esophagus, stomach, and kidney tissue (Figure 1). Weak positive TK1 expression was found in normal lung, liver, colon, and rectum tissues (Figure 1). There was no significant difference between carcinoma and normal uterus tissue. Unfortunately, only two normal uterine tissues were available for this analysis and more tissue is needed to confirm these findings. TK1 expression was significantly higher in tumor tissue of the esophagus, stomach, colon, liver, lung and kidney compared to normal tissue (Table 1). Each of the tissues was also stained with an isotype control (mouse IgG, Upstate Company), and all tumor and normal tissue was negative. 

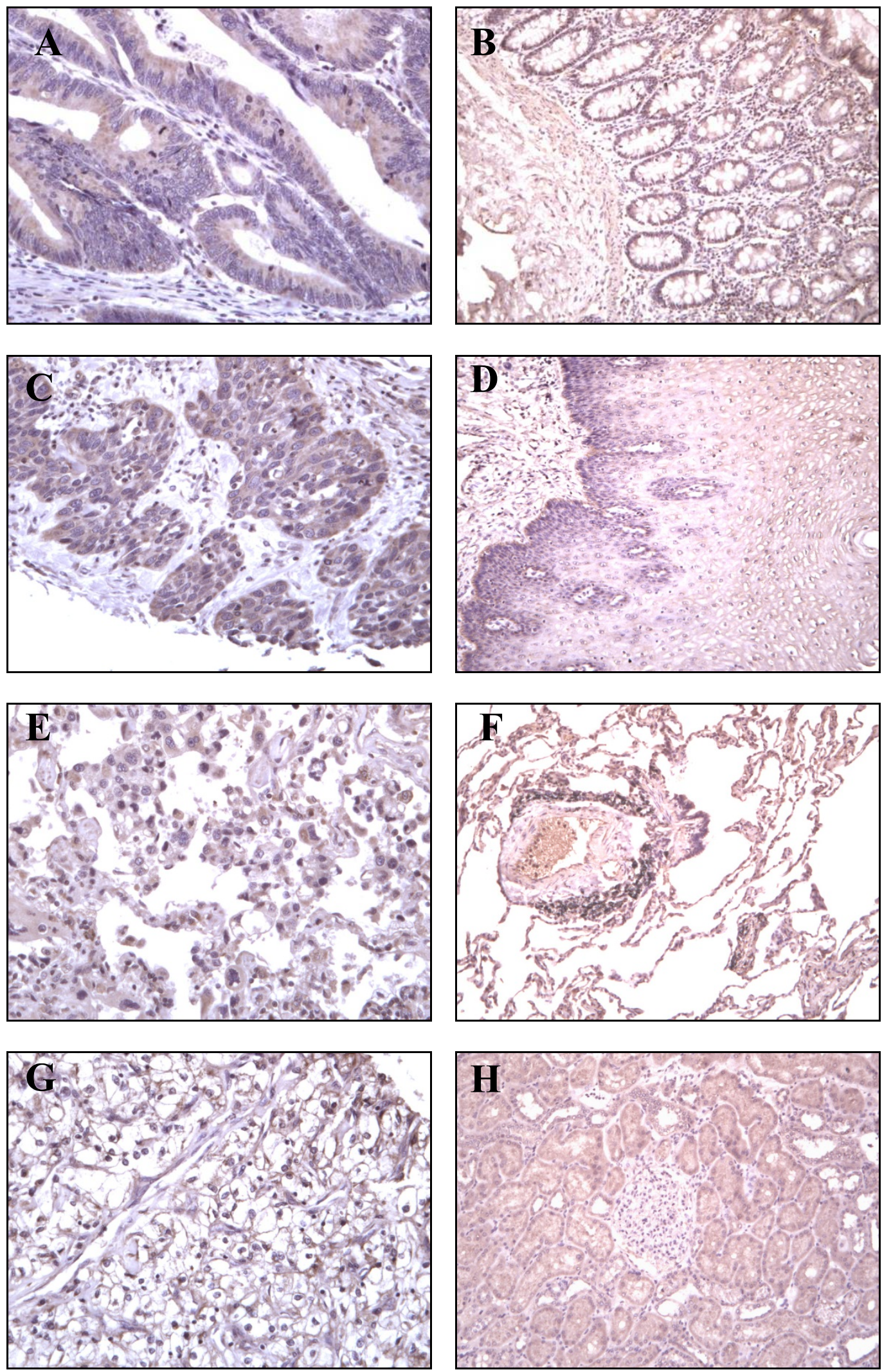

Figure 1. TK1 multi-organ tissue staining

Cytoplasmic TK1 staining was found in A) colon adenocarcinoma, C) esophageal squamous cell carcinoma, E) lung adenocarcinoma, and G) kidney clear cell carcinoma tissues. None or weak TK1 staining can be found in normal B) colon, D) esophagus, F) lung, and H) kidney tissues. 
Table 1. TK1 staining in normal and carcinoma tissue

\begin{tabular}{|c|c|c|c|c|c|c|}
\hline & & Negative & Weak Positive & Positive & Total & Significance \\
\hline \multirow[t]{2}{*}{ Liver } & Normal & 0 & 6 & 0 & 6 & 0.001 \\
\hline & Carcinoma & 0 & 0 & 6 & 6 & \\
\hline \multirow[t]{2}{*}{ Stomach } & Normal & 6 & 0 & 0 & 6 & 0.014 \\
\hline & Carcinoma & 1 & 3 & 2 & 6 & \\
\hline \multirow[t]{2}{*}{ Esophagus } & Normal & 4 & 1 & 0 & 5 & 0.016 \\
\hline & Carcinoma & 0 & 2 & 4 & 6 & \\
\hline \multirow[t]{2}{*}{ Kidney } & Normal & 6 & 0 & 0 & 6 & 0.001 \\
\hline & Carcinoma & 0 & 0 & 6 & 6 & \\
\hline \multirow[t]{2}{*}{ Uterus } & Normal & 0 & 0 & 2 & 2 & 0.29 \\
\hline & Carcinoma & 0 & 2 & 3 & 5 & \\
\hline \multirow[t]{2}{*}{ Colon } & Normal & 0 & 6 & 0 & 6 & 0.014 \\
\hline & Carcinoma & 3 & 1 & 2 & 6 & \\
\hline \multirow[t]{2}{*}{ Lung } & Normal & 0 & 5 & 0 & 5 & 0.022 \\
\hline & Carcinoma & 0 & 2 & 4 & 6 & \\
\hline
\end{tabular}

Interestingly, the normal tissue included in this study was initially taken from the margins around the tumor. These margins from cancer patients were considered normal using current pathological methods. However, recent studies have indicated that the normal microenvironment surrounding a tumor in many cases is altered and has lost its normal regulation (Alegre et al., 2012; Farmaki et al., 2012; Niu et al., 2012). Previous studies have suggested that this may help explain some TK1 positive staining in these normal tumor margins (Alegre et al., 2012). Therefore, we obtained normal tissue from 100 noncancerous individuals, called true normal tissue, which included 34 true normal organs (Cybrdi Inc, Frederick MD). TK1 cytoplasmic staining was found in adrenal gland cells, germ cells of the seminiferous tubules of the testis, and hematopoietic cells of the bone marrow (Figure 2). Weak background staining was seen in tubular cells of the kidney, cardiac and striated muscle cells, salivary gland duct cells, mucous secreting cells in small intestine and stomach, and transitional cells of the ureter and bladder (Figure 2). No other true normal organs stained positive for TK1, including those normal tumor margins which previously showed weak positive staining for TK1.
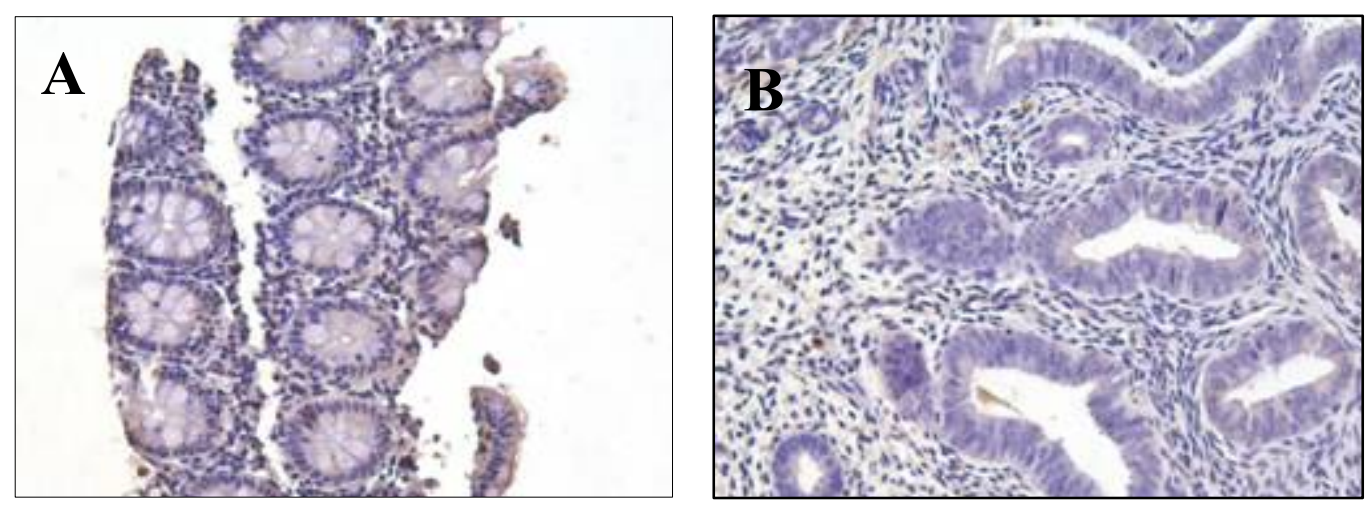

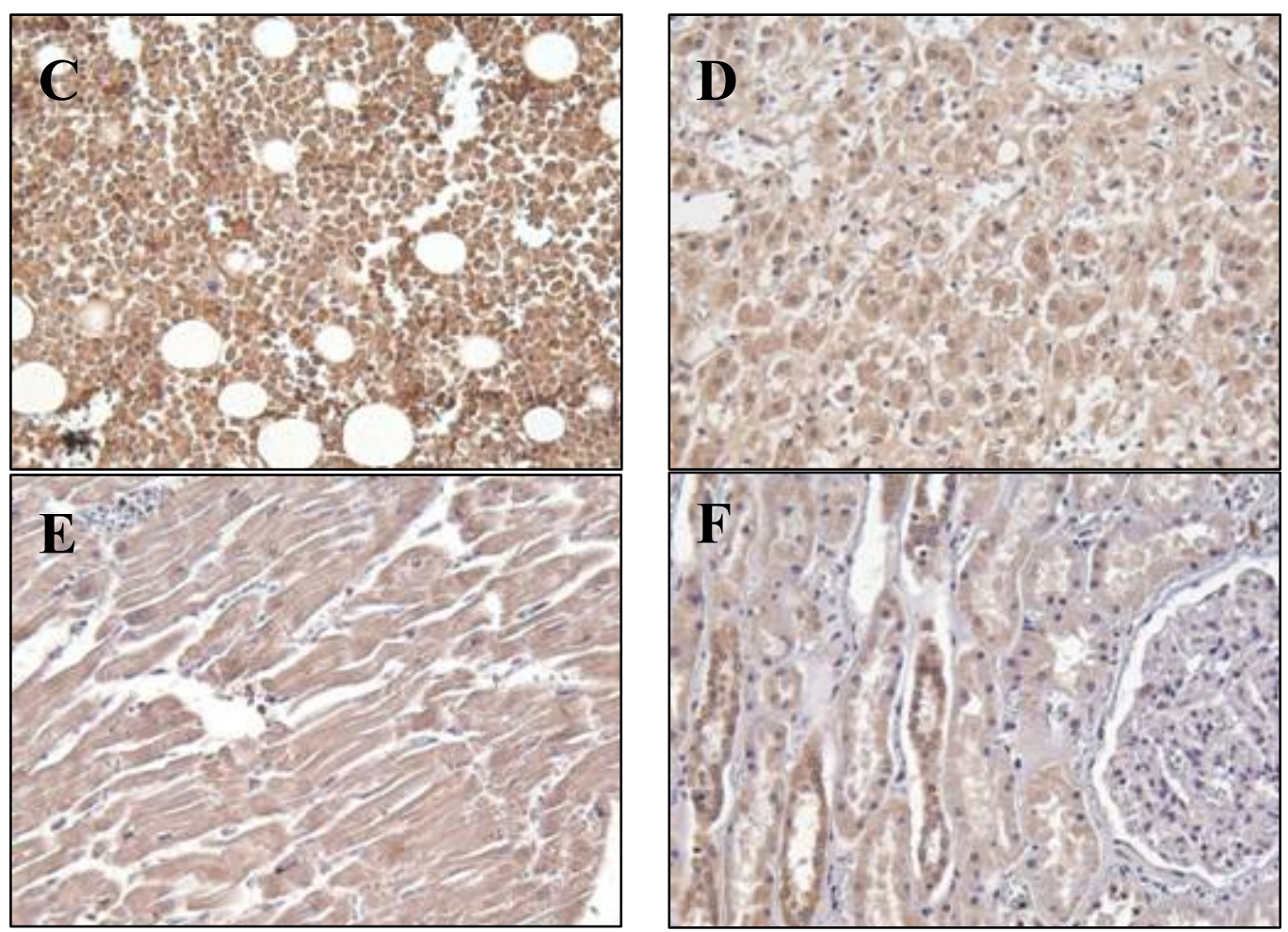

Figure 2. TK1noncancerous true normal staining

No TK1 staining could be found in A) true normal colon, and B) true normal uterus tissue. Cytoplasmic TK1 staining was found in C) true normal bone marrow and D) true normal adrenal gland. Weak positive TK1 staining was found in E) true normal cardiac tissue and F) true normal kidney tissue.

\subsection{A Marker for the \#1 Cancer Killer in Men: TK1 and Lung Cancer}

Since the majority of cancer mortality in men is due to lung cancer, we investigated the link between TK1 staining and lung cancer more thoroughly. TK1 expression was evaluated in 376 lung cancer tissue cores representing 172 individuals and 63 normal lung cores from 29 individuals. Samples represented a variety of lung cancer diagnoses including small cell carcinoma, large cell carcinoma, adenocarcinoma, squamous cell carcinoma, adenosquamous cell carcinoma, bronchioloalveolar carcinoma, mucinous adenocarcinoma, undifferentiated carcinoma, neuroendocrine carcinoma, papillary carcinoma, mesothelioma, and sarcoma. Combining all lung cancer tissues, there is a highly statistically significant difference between TK1 expression in lung cancer and normal lung tissue $(\mathrm{p}<0.0001)$. In this study, we only had access to one mucinous adenocarcinoma and one papillary carcinoma, and both cases showed positive TK1 expression, but further samples should be tested to confirm this finding. Neuroendocrine carcinoma tissues were not significantly different in TK1 expression compared to normal lung tissue. All other lung cancer groups showed significantly higher TK1 expression compared to normal controls including small cell carcinoma, large cell carcinoma, adenocarcinoma, squamous cell carcinoma, undifferentiated carcinoma, mesothelioma, bronchioloalveolar carcinoma, adenosquamous cell carcinoma, and sarcoma (Table 2). There was also a statistically significant difference in TK1 expression between small cell lung cancer and non-small cell lung cancer $(\mathrm{p}<0.0001)$ in which non-small cell lung cancer exhibited higher TK1 expression. Additionally, squamous cell carcinoma had significantly higher TK1 expression compared to adenocarcinoma tissues $(p<0.0001)$, but squamous cell carcinoma was not significantly different from large cell carcinoma. Although each of the individual lung cancer diagnosis groups differed slightly, all were significantly higher than normal lung tissue, indicating that TK1 may be a valuable marker for lung cancer. 
Table 2. TK1 staining in various types of lung cancer

\begin{tabular}{|c|c|c|c|c|c|c|}
\hline & Negative & Weak Positive & Positive & Strong Positive & Total & Significance \\
\hline Small Cell Carcinoma & 11 & 26 & 0 & 0 & 37 & 0.0018 \\
\hline Large Cell Carcinoma & 5 & 6 & 1 & 7 & 19 & $<0.0001$ \\
\hline Adenocarcinoma & 13 & 5 & 8 & 0 & 26 & $<0.0001$ \\
\hline Squamous Cell Carcinoma & 3 & 10 & 18 & 5 & 36 & $<0.0001$ \\
\hline Bronchioloalveolar Carcinoma & 0 & 3 & 2 & 0 & 5 & $<0.0001$ \\
\hline Adenosquamous Cell Carcinoma & 0 & 1 & 2 & 1 & 4 & $<0.0001$ \\
\hline Undifferentiated Carcinoma & 0 & 2 & 2 & 0 & 4 & 0.0002 \\
\hline Neuroendocrine Carcinoma & 0 & 0 & 2 & 1 & 3 & 0.0755 \\
\hline Sarcoma & 0 & 1 & 1 & 0 & 2 & 0.025 \\
\hline Mesothelioma & 0 & 0 & 2 & 0 & 2 & 0.0016 \\
\hline Mucinous Adenocarcinoma & 0 & 0 & 1 & 0 & 1 & - \\
\hline Papillary Carcinoma & 0 & 0 & 1 & 0 & 1 & - \\
\hline Normal Lung & 24 & 4 & 1 & 0 & 29 & - \\
\hline
\end{tabular}

\subsection{A Marker for the \#2 Cancer Killer in Men: TK1 and Prostate Cancer}

Prostate cancer is responsible for a large portion of cancer mortality in men, second only to lung cancer. Due to this high prevalence in both mortality and incidence, we sought to determine whether TK1 histological staining could also be used as a marker for prostate cancer. TK1 expression was evaluated in 57 prostate tissues which represented 20 individuals. Each individual was represented by 3 different tissue cores including normal, hyperplasia, or carcinoma tissues. Each tissue was also stained with an isotype control (mouse IgG, Upstate Company) and all these isotype-stained tissues were negative. The majority of prostate adenocarcinoma tissue exhibited TK1 cytoplasmic positive staining which was significantly different compared to either normal or hyperplasia tissues $(\mathrm{p}<0.0001)$ (Table 3). Additionally, TK1 expression increased as prostate adenocarcinoma advanced from grade 1 to grade $3(\mathrm{p}=0.004)$ (Figure 3$)$. This confirms our previous findings that TK1 is a valuable marker of malignancy and is expressed in the very early stages of cancer.

Table 3. TK1 staining in prostate cancer

\begin{tabular}{lcccc}
\hline & Negative & Positive & Total & Significance \\
\hline Normal & 9 & 8 & 17 & \\
Hyperplasia & 6 & 0 & 6 & \\
Adenocarcinoma & 5 & 27 & 32 & $<0.0001$ \\
Adenocarcinoma grade 1 & 0 & 1 & 1 & \\
Adenocarcinoma grade 2 & 3 & 4 & 7 & \\
Adenocarcinoma grade 3 & 0 & 22 & 22 & 0.004 \\
\hline
\end{tabular}



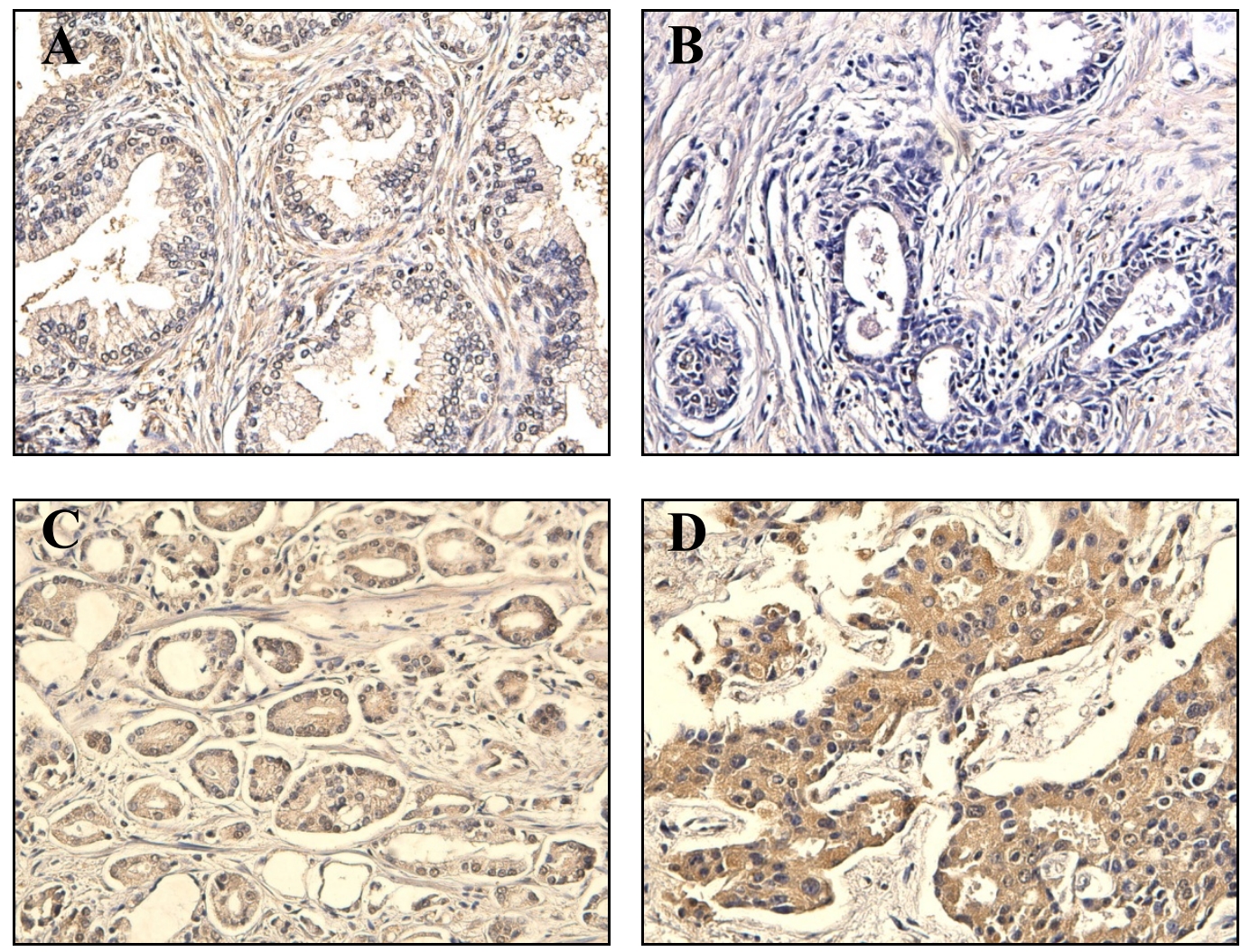

Figure 3. TK1 staining in prostate cancer

No TK1 staining was found in A) normal prostate and B) prostate hyperplasia. Cytoplasmic TK1 staining was found in C) prostate carcinoma grade 2 and D) prostate carcinoma grade 3 . There was a significant increase in TK1 expression from prostate carcinoma grade 1 to grade 3 .

\section{Discussion}

This is the first study to do an overall comparison and analysis of TK1 expression among a variety of malignant tissues. It is clear that TK1 is a good marker for malignancy as it is significantly increased in a variety of carcinoma tissues. For example, as the data in Table 1 indicates, there is a highly significant difference between normal and carcinoma tissues for virtually all organ types. From this we determined that TK1 is a good marker of malignancy in at least seven of the most common types of cancer, including lung, colon, prostate, esophagus, stomach, liver, and kidney. Typically, if TK1 is expressed in normal tissue, it is very weak and insignificant compared to the isotype control. Although there was no significant difference in TK1 expression between normal and carcinoma uterine tissues in our study, several other studies have demonstrated that TK1 can be used as a marker for uterine malignancy (Shintani, Urano, Takakuwa, Kuroda, \& Kamoshidai, 2010). Additionally, TK1 as a marker for breast cancer and hematological malignancies, has been well-established by previous studies (Aufderklamm et al., 2012). Together, this indicates that TK1 appears to be a good universal marker for cancer among both solid and hematological malignancies.

Previous studies have demonstrated that TK1 overexpression is an early event in cancer, both in the serum of cancer patients and in primary tumors (Guan et al., 2009; S. Huang et al., 2011). Interestingly, our study revealed that TK1 is expressed in some normal tissue (Table 1). However, this tissue was taken from the tumor margins and considered normal using current pathology standards. On the other hand, the same organ tissue taken from noncancerous individuals, called true normal tissue, did not express TK1. Due to the early diagnostic nature of TK1, it may be that these normal tumor margins may in fact be precancerous lesions which are considered normal by current pathology standards. Perhaps, these cells which normally remain undetected may play a role in the development of recurrent lesions. It would be interesting to follow the patients with TK1 positive tumor margins to determine if those patients later relapsed or showed worse prognosis. Unfortunately, no follow-up data was available and we could not determine the clinical significance of TK1 positive tumor margins.

Of particular note, TK1 expression is a good marker for both lung and prostate cancer, the two most frequently 
diagnosed and leading causes of cancer-related deaths in men (Siegel et al., 2013). Although there are slight differences in the staining patterns of lung cancer, virtually all types of lung cancer had higher TK1 expression which was highly significantly different compared to normal lung tissues (Table 2). Prostate cancer tissues showed similar trends and even showed increasing TK1 expression from grade 1 to grade 3 prostate carcinoma tissues.

\section{Conclusion}

Our results indicate that TK1 expression is significantly higher in malignancy compared to normal tissue. TK1 appears to have potential as a tumor marker in a wide variety of malignancies, including at least seven of the most common types, and thus may be a useful universal cancer marker.

\section{References}

Alegre, M. M., Robison, R. A., \& O'Neill, K. L. (2012). Thymidine Kinase 1 Upregulation Is an Early Event in Breast Tumor Formation. J Oncol, 2012, 575647. http://dx.doi.org/10.1155/2012/575647

Aufderklamm, S., Todenhofer, T., Gakis, G., Kruck, S., Hennenlotter, J., Stenzl, A., \& Schwentner, C. (2012). Thymidine kinase and cancer monitoring. Cancer Lett, 316(1), 6-10. http://dx.doi.org/10.1016/j.canlet.2011.10.025

Chen, Z. H., Huang, S. Q., Wang, Y. D., Yang, A. Z., Wen, J., Xu, X. H., ... Skog, S. (2011). Serological Thymidine Kinase 1 is a Biomarker for Early Detection of Tumours-A Health Screening Study on 35,365 People, Using a Sensitive Chemiluminescent Dot Blot Assay. Sensors, 11(12), 11064-11080. http://dx.doi.org/10.3390/s111211064

Farmaki, E., Chatzistamou, I., Bourlis, P., Santoukou, E., Trimis, G., Papavassiliou, A. G., \& Kiaris, H. (2012). Selection of p53-Deficient Stromal Cells in the Tumor Microenvironment. Genes Cancer, 3(9-10), 592-598. http://dx.doi.org/10.1177/1947601912474002

Guan, H., Sun, Y., Zan, Q., Xu, M., Li, Y., Zhou, J., ... Skog, S. (2009). Thymidine kinase 1 expression in atypical ductal hyperplasia significantly differs from usual ductal hyperplasia and ductal carcinoma in situ: A useful tool in tumor therapy management. Mol Med Report, 2(6), 923-929. http://dx.doi.org/10.3892/mmr_00000193

He, Q., Mao, Y., Wu, J., Decker, C., Merza, M., Wang, N., ... Skog, S. (2004). Cytosolic thymidine kinase is a specific histopathologic tumour marker for breast carcinomas. Int J Oncol, 25(4), 945-953.

He, Q., Skog, S., \& Tribukait, B. (1991). Cell cycle related studies on thymidine kinase and its isoenzymes in Ehrlich ascites tumours. Cell Prolif, 24(1), 3-14. http://dx.doi.org/10.1111/j.1365-2184.1991.tb01506.x

Huang, S., Lin, J., Guo, N., Zhang, M., Yun, X., Liu, S., ... Skog, S. (2011). Elevated serum thymidine kinase 1 predicts risk of pre/early cancerous progression. Asian Pac J Cancer Prev, 12(2), 497-505.

Huang, Z. H., Tian, X. S., Li, R., Wang, X. M., Wen, W., Guan, H., \& Yang, Y. J. (2012). Elevated thymidine kinase 1 in serum following neoadjuvant chemotherapy predicts poor outcome for patients with locally advanced breast cancer. Experimental and Therapeutic Medicine, 3(2), 331-335. http://dx.doi.org/10.3892/etm.2011.395

Li, Z., Wang, Y., He, J., Ma, J., Zhao, L., Chen, H., ... Skog, S. (2010). Serological thymidine kinase 1 is a prognostic factor in oesophageal, cardial and lung carcinomas. Eur J Cancer Prev, 19(4), 313-318. http://dx.doi.org/10.1097/CEJ.0b013e32833ad320

Liu, Y. P., Ling, Y., Qi, Q. F., Tang, Y. X., Xu, J. Z., Zhou, T., ... Pan, Y. D. (2011). Changes in serum thymidine kinase 1 levels during chemotherapy correlate with objective response in patients with advanced gastric cancer. Experimental and Therapeutic Medicine, 2(6), 1177-1181. http://dx.doi.org/10.3892/etm.2011.338

Niu, H., Jiang, H., Cheng, B., Li, X., Dong, Q., Shao, L., ... Wang, X. (2012). Stromal proteome expression profile and muscle-invasive bladder cancer research. Cancer Cell Int, 12(1), 39. http://dx.doi.org/10.1186/1475-2867-12-39

O'Neill, K. L., Buckwalter, M. R., \& Murray, B. K. (2001). Thymidine kinase: diagnostic and prognostic potential. Expert Rev Mol Diagn, 1(4), 428-433. http://dx.doi.org/10.1586/14737159.1.4.428

O'Neill, K. L., Zhang, F., Li, H., Fuja, D. G., \& Murray, B. K. (2007). Thymidine kinase 1--a prognostic and diagnostic indicator in ALL and AML patients. Leukemia, 21(3), 560-563. http://dx.doi.org/10.1038/sj.leu.2404536 
Shintani, M., Urano, M., Takakuwa, Y., Kuroda, M., \& Kamoshidai, S. (2010). Immunohistochemical characterization of pyrimidine synthetic enzymes, thymidine kinase-1 and thymidylate synthase, in various types of cancer. Oncology Reports, 23(5), 1345-1350. http://dx.doi.org/10.3892/or_00000770

Siegel, R., Naishadham, D., \& Jemal, A. (2013). Cancer statistics, 2013. CA: A Cancer Journal for Clinicians, 63(1), 11-30. http://dx.doi.org/10.3322/caac.21166

Wu, B. J., Li, W. P., Qian, C., Ding, W., Zhou, Z. W., \& Jiang, H. (2013). Increased serum level of thymidine kinase 1 correlates with metastatic site in patients with malignant melanoma. Tumour Biol, 34(2), 643-648. http://dx.doi.org/10.1007/s13277-012-0591-0

Xu, W., Shen, Q. D., Yu, H., Qiao, C., Wu, Y. J., Liu, Q., ... Li, J. Y. (2009). [Lipoprotein lipase and serum thymidine kinase level in chronic lymphocytic leukemia and their correlations with other prognostic factors]. Zhonghua Xue Ye Xue Za Zhi, 30(1), 8-12. 